\title{
An Ecological Dynamics Model of Algae Growth in Taihu Lake and the Analysis of Its Influencing Factors
}

\author{
Qingquan Liư ${ }^{1, a}$, Yong Gao ${ }^{1}$, Xufeng $\mathrm{Xu}^{1}$ \\ ${ }^{1}$ Lab. Environmental Fluid Mechanics, Institute of Mechanics, CAS, Beijing 100190, China \\ âEmail: qqliu@imech.ac.cn
}

Keywords: Taihu Lake, ecological dynamics model, water quality, eutrophication, algae growth.

\begin{abstract}
For the study on the eutrophication problem in Taihu Lake of China, an ecological dynamics model of algae growth is established based on the simulation of the growth of the dominating algae in Taihu Lake. Chlorophyll-a (chl-a), total phosphorus (TP) and total nitrogen (TN) are chosen to be the water quality variables. The main factors influencing the algae growth in Taihu Lake are investigated by the sensitivity analysis of the model's parameters. The results show that the maximum growth rate of algae, the algae respiration rate, the coefficients of temperature influence and the half saturation constant for phosphorus have significant influences on the simulation results. Temperature and TP are the dominating factors of influencing the algae growth in Taihu Lake.
\end{abstract}

\section{Introduction}

The concern of lake eutrophication focuses on abundant algal growth. Algae in eutrophic lakes will grow rapidly under proper conditions such as high temperature and enough light illumination. And the formation of algal blooms results in serious deterioration in water quality. Taihu Lake, located in the economically developed Yangtze River Delta, is China's third largest freshwater lake and an important freshwater resources for the local economy and people's life. Taihu Lake is a typical large shallow lake, with an area of about $2338 \mathrm{~km}^{2}$ and the average depth of only $1.9 \mathrm{~m}$. Recently, due to the rapid development of industry and agriculture, the environment in Taihu Lake is becoming worse which leads to serious eutrophication problem and frequent outbreaks of water blooms.

It is an effective way to quantitatively study the eutrophication problem by using numerical methods in simulating ecological models [1]. During the last two decades, a lot of ecological dynamics models are developed for the research of algae ecosystem in lakes [2,3,4], with lots of ecological processes considered and many water quality variables involved $[5,6,7]$. Such models are complex, and there are still few accurate models which are very suitable for the Taihu Lake study considering its actual conditions. So it is of great significance to develop a proper ecological dynamics model for the management of eutrophication problem in Taihu Lake. In this paper, on the basis of previous studies, an ecological dynamics model focusing on the growth of dominating algae in Taihu Lake is developed to analyze the influencing factors of algae growth in Taihu Lake. The results will give some scientific support for the eutrophication problem in Taihu Lake.

\section{Ecological Dynamics Model for Taihu Lake}

In recent decades, the species of phytoplankton in Taihu Lake have reduced but the amount increased. Moreover, the dominating species changed, from blue-green algae and diatoms in the 1950s to 1980s to blue-green algae and cryptophyta in the 1990s and after the year 2000 they become blue-green algae, green algae and diatoms, in which Microcystis aeruginosa has the greatest advantage. Microcystis aeruginosa have a high capacity to absorb the inorganic phosphorus of low concentration, which makes them more competitive. Thus Microcystis aeruginosa has become the dominating species in Taihu Lake and the main constituent during water blooms.

The growth of algae is affected by light, temperature, nutrients and many other conditions. Meanwhile, respiration process consumes organic matter, death as well as sedimentation of algae also decreases the algal biomass. Under certain conditions, nitrogen and phosphorus are taken up by algae, 
and converted into organic nitrogen/phosphorus by photosynthesis. On the other hand, death and respiration of algae will decrease the algal biomass, releasing the nutrients into water through biological and chemical processes. In addition, sedimentation and mineralization are in the cycle of algae and nutrients. Generally the ecological dynamics process of algae in lakes is shown in Fig. 1:

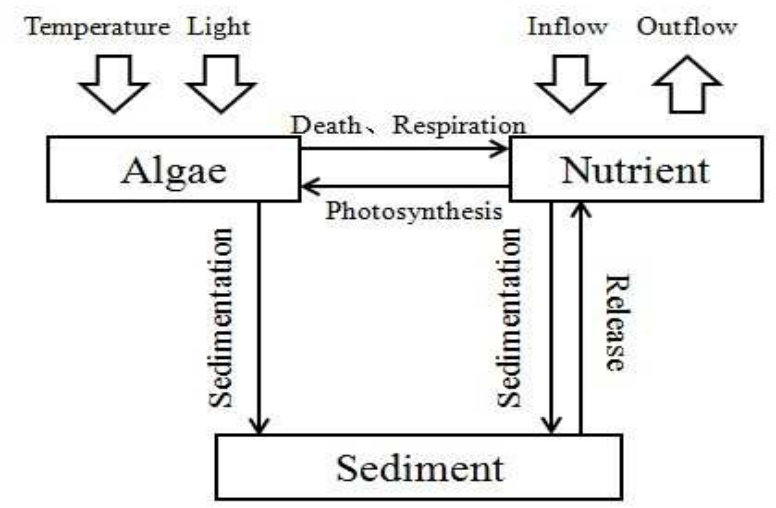

Fig. 1 Ecological dynamics process of algae in model

Using chlorophyll concentration as the phytoplankton (algae) indicator, the ecological dynamics model of algae growth can be expressed as following form:

$$
\frac{\partial C_{A}}{\partial t}=\left(R_{G}-R_{D}-\frac{v_{s}}{H}\right) C_{A}
$$

where, $C_{A}$ is the concentration of chlorophyll; $R_{G}$ is the growth rate of algae, which is limited by the factors of light, temperature and nutrients; $R_{D}$ is the loss rate of algae, including respiration rate and death rate; $v_{s}$ is the sedimentation of algae.

Growth Rate of Algae. The growth rate of algae is limited by the factors of light intensity, water temperature and nutrients, which can be expressed as:

$$
R_{G}=\mu_{\max } f(I) f(T) f(N P)
$$

where, $\mu_{\max }$ is the maximum growth rate of algae, $f(\mathrm{I})$ the limitation due to light, $f(\mathrm{~T})$ the limitation due to temperature, $f(\mathrm{NP})$ the limitation due to nutrients.

Algal production increases as a function of light intensity until an optimal intensity is reached, and beyond that optimal value, the speed of production increasing declines. Considering the light extinction efficient in water proposed by Di Toro and Smith et al. and the inhibition of intense light, the formulation of the limitation due to light can be expressed as:

$$
f(I)=\frac{I}{I_{S}} \exp \left(1-\frac{I}{I_{S}}\right)
$$

Where $I_{S}$ is the optimal illumination rate.

The growth rate of algae is directly related to water temperature. For the Microcystis which is the dominating algae in Taihu Lake, the rate of photosynthesis increases with temperature exponentially during the range of $10-30{ }^{\circ} \mathrm{C}$, but decreases when the temperature is over $35{ }^{\circ} \mathrm{C}$. So $30{ }^{\circ} \mathrm{C}$ is the temperature for optimal growth. Considering the optimal temperature $T_{o p t}$, the limitation due to temperature can be expressed as:

$$
f(T)=1-\frac{\left(T-T_{o p t}\right)^{2}}{\left(T_{o p t}\right)^{2}}
$$


For most planktonic algae, nitrogen and phosphorus are the main limiting factors. Based on the Liebig's law of minimum, the growth of algae is controlled by the scarcest nutrient. The relationship between limiting nutrients and algae growth rate is given as the Monod's equation:

$$
f(N P)=\min \left(\frac{C_{T P}}{K_{P}+C_{T P}}, \frac{C_{T N}}{K_{N}+C_{T N}}\right)
$$

Where, $C_{T P}$ is the concentration of TP, $C_{T N}$ the concentration of TN, $K_{P}$ the half saturation constant for phosphorus, and $K_{N}$ the half saturation constant for nitrogen. The half saturation constant is the concentration at which the limiting factor is 0.5 .

Loss Rate of Algal Biomass. The process causing loss of algal biomass includes respiration, death, and sedimentation of algae and the predation of zooplankton. Neglecting the predation of zooplankton, the loss rate of algae biomass can be expressed as:

$$
R_{D}=k_{R} \theta_{R}^{T-20}+k_{D}
$$

Where $k_{R}$ is the respiration rate of algae, $\theta_{R}$ the coefficient of temperature influence on respiration, $k_{D}$ the death rate of algae. Rate of respiration varies similar to photosynthesis with temperature.

Cycle Processes of TP and TN. Phosphorus exists in water with different forms, including planktonic phosphorus, organic phosphorus and inorganic phosphorus. Considering the absorption of algae growth, releasing by death, sedimentation and releasing from sediment, the dynamic process of TP in water can be expressed as:

$$
\frac{d C_{T P}}{d t}=a_{P}\left(R_{D}-R_{G}\right) C_{A}-v_{P} C_{T P}+\frac{d_{P}}{H}
$$

Where, $a_{P}$ is the phosphorus-carbon ratio, representing the content of phosphorus in algae, $v_{P}$ the sedimentation rate of phosphorus, and $d_{P}$ the release rate of phosphorus.

Nitrogen exists in water with different forms too, including planktonic nitrogen, organic nitrogen and inorganic nitrogen. Similar to the phosphorus cycle, the dynamic process of TN in water can be expressed as:

$$
\frac{d C_{T N}}{d t}=a_{N}\left(R_{D}-R_{G}\right) C_{A}-v_{N} C_{T N}+\frac{d_{N}}{H} .
$$

Where, $a_{N}$ is the nitrogen-carbon ratio, representing the content of nitrogen in algae, $v_{N}$ the sedimentation rate of nitrogen, and $d_{N}$ the release rate of nitrogen.

\section{Parameters in the Model}

It is not easy to determine and calibrate the values of the parameters in the model due to lacking of filed data and the complex environmental conditions in Taihu Lake. In this study, model parameters are determined by the experimental or calculated results given by previous research [8,9]. Table 1 shows the parameter values used in the model.

Table1 Parameters used in the model

\begin{tabular}{lccc}
\hline \multicolumn{1}{c}{ Description } & Parameter & Unit & Value \\
\hline Maximum growth rate of algae & $\mu_{\max }$ & $d^{-1}$ & 1.27 \\
Respiration rate of algae & $k_{R}$ & $d^{-1}$ & 0.4 \\
Death rate of algae & $k_{D}$ & $d^{-1}$ & 0.1
\end{tabular}


Optimal(Saturation) light intensity

Coefficient of temperature influence on growth

Coefficient of temperature influence on respiration

Half saturation constant for phosphorus

Half saturation constant for nitrogen

Phosphorus-carbon ratio

$\begin{array}{ccc}I_{S} & \mu E /\left(m^{2} \cdot s\right) & 600 \\ \theta_{G} & 1 & 1.068 \\ \theta_{R} & 1 & 1.045 \\ K_{P} & m g / L & 0.025 \\ K_{N} & m g / L & 0.17 \\ a_{P} & m g(P) / m g(C) & 0.025 \\ a_{N} & m g(N) / m g(C) & 0.25 \\ v_{s} & m / d & 0.024 \\ v_{P} & d^{-1} & 0.01 \\ v_{N} & d^{-1} & 0.015 \\ d_{P} & g /\left(m^{2} \cdot d\right) & 0.0011 \\ d_{N} & g /\left(m^{2} \cdot d\right) & 0.0034\end{array}$

Nitrogen-carbon ratio

Settling velocity of algae

Sedimentation rate of phosphorus

Sedimentation rate of nitrogen

Release rate of phosphorus

$g /\left(m^{2} \cdot d\right)$

0.0034

\section{Sensitivity Analysis of Influencing Factors}

Initial values of nutrients in Taihu Lake are determined by the average concentration in the year of 2005, with TP 5800 ton and TN 98200 ton. The light intensity is equal to $1500 \mu E /\left(\mathrm{m}^{2} \cdot \mathrm{s}\right)$, which is the average value during summer in Taihu Lake. Initial water temperature is set to $25^{\circ} \mathrm{C}$, and then reduces $0.25^{\circ} \mathrm{C}$ per day for 60 days. The parameters are set to be a constant except one parameter $x_{i}$ (givin a certain percentage of increase and decrease) during the simulation, then the influence of the parameter is got by analysing the concentration of the water quality variables from the simulation results. The relative sensitivity coefficient is defined as: $s_{i}=(\Delta c / c) /\left(\Delta x_{i} / x_{i}\right)$. Fig. 2 shows the simulated results of influence on the algae growth by eight factors (maximum growth rate, respiration rate, death rate, settling velocity of algae, coefficient of temperature influence on growth, coefficient of temperature influence on respiration, half saturation constant for phosphorus and half saturation constant for nitrogen). Meanwhile, the sensitivity coefficients from the factors are given in Table 2.

Table 2 Relative sensitivity coefficients from eight influencing factors

\begin{tabular}{|c|c|c|c|c|c|}
\hline Parameter & $\begin{array}{l}\text { Value } \\
\left(x_{i}\right)\end{array}$ & $\begin{array}{l}\text { Variation } \\
\left(\Delta x_{i} / x_{i}\right)\end{array}$ & Indicator & $\begin{array}{c}\text { Maximum } \\
\text { influence }(\Delta c / c)\end{array}$ & $\begin{array}{l}\text { Relative sensitivity } \\
\text { coefficience }\left(s_{i}\right)\end{array}$ \\
\hline \multirow{2}{*}{$\mu_{\max }$} & \multirow{2}{*}{1.27} & $10 \%$ & Chla & 3.05 & 30.5 \\
\hline & & $-10 \%$ & Chla & -0.8 & 8 \\
\hline \multirow{2}{*}{$k_{R}$} & \multirow{2}{*}{0.4} & $10 \%$ & Chla & -0.68 & -6.8 \\
\hline & & $-10 \%$ & Chla & 1.91 & -19.1 \\
\hline \multirow{2}{*}{$k_{D}$} & \multirow{2}{*}{0.1} & $10 \%$ & Chla & -0.22 & -2.2 \\
\hline & & $-10 \%$ & Chla & 0.27 & -2.7 \\
\hline \multirow{2}{*}{$v_{s}$} & \multirow{2}{*}{0.024} & $10 \%$ & Chla & -0.03 & -0.3 \\
\hline & & $-10 \%$ & Chla & 0.03 & -0.3 \\
\hline \multirow{2}{*}{$\theta_{G}$} & \multirow{2}{*}{1.068} & $1 \%$ & Chla & 0.29 & 29 \\
\hline & & $-1 \%$ & Chla & -0.23 & 23 \\
\hline \multirow{2}{*}{$\theta_{R}$} & \multirow{2}{*}{1.045} & $1 \%$ & Chla & -0.17 & -17 \\
\hline & & $-1 \%$ & Chla & 0.19 & -19 \\
\hline \multirow{2}{*}{$K_{P}$} & \multirow{2}{*}{0.025} & $10 \%$ & Chla & -0.31 & -3.1 \\
\hline & & $-10 \%$ & Chla & 0.45 & -4.5 \\
\hline \multirow{2}{*}{$K_{N}$} & \multirow{2}{*}{0.17} & $10 \%$ & Chla & 0 & 0 \\
\hline & & $-10 \%$ & Chla & 0 & 0 \\
\hline
\end{tabular}




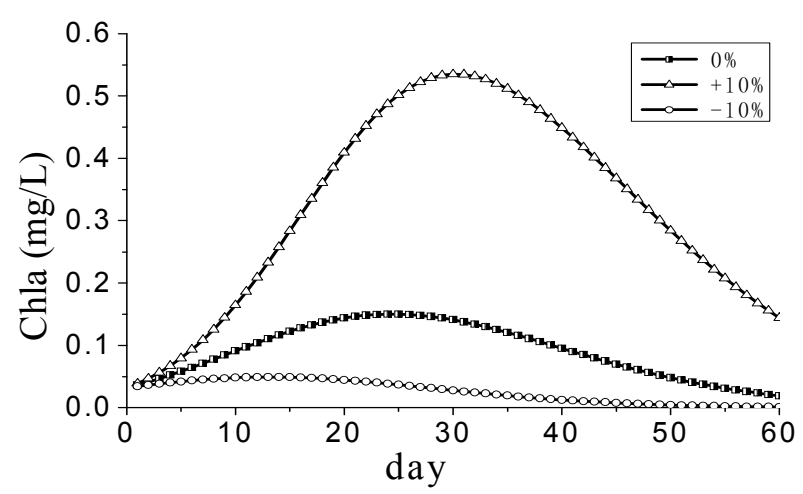

(a ) maximum growth rate of algae

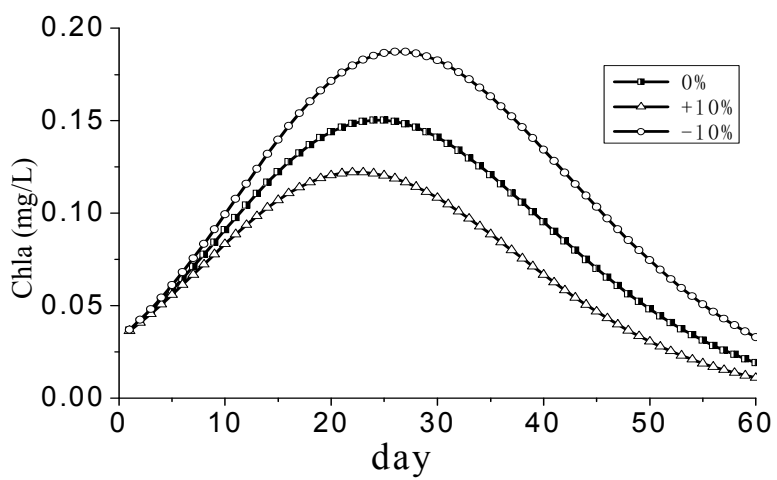

(c) death rate of algae

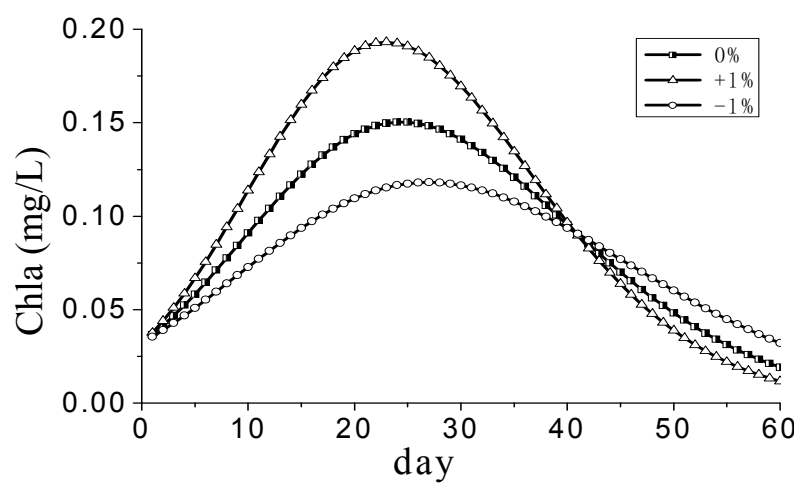

(e) coefficient of temperature influence on growth

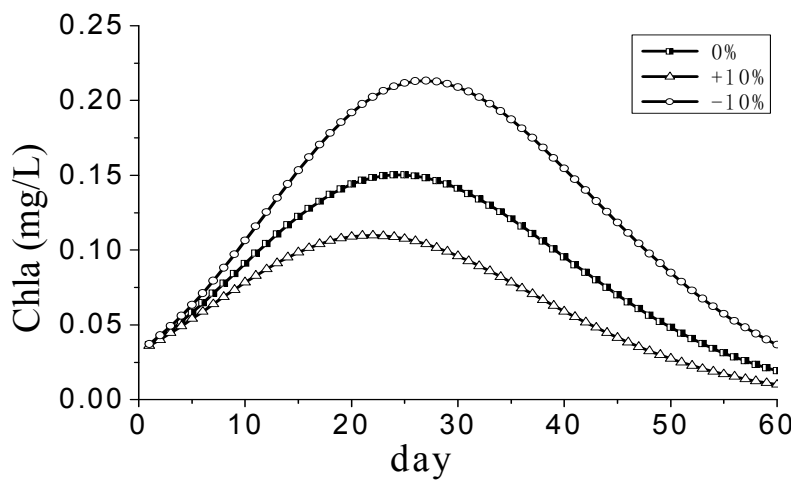

(g) half saturation constant for phosphorus

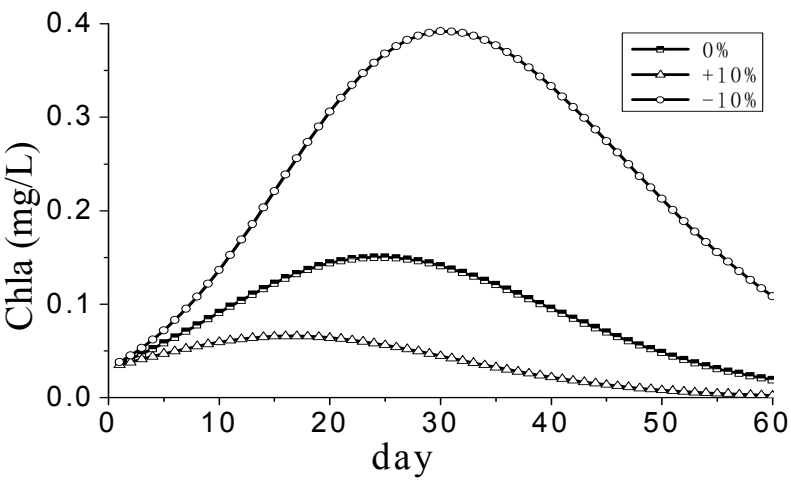

(b) respiration rate of algae

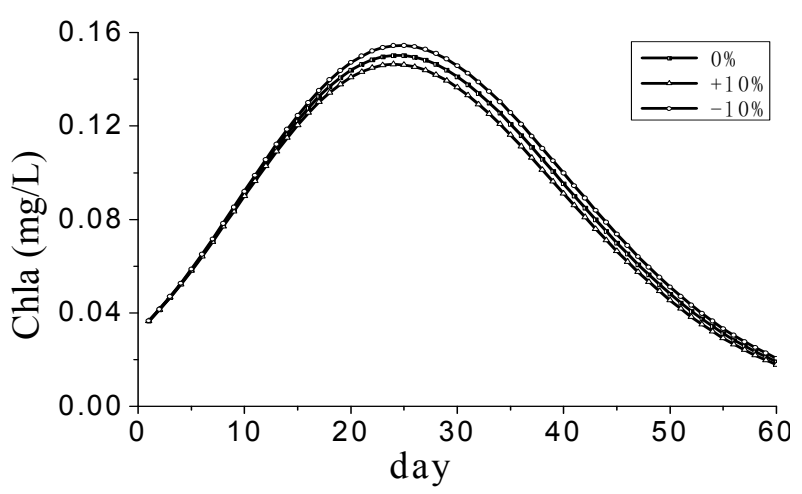

(d) settling velocity of algae

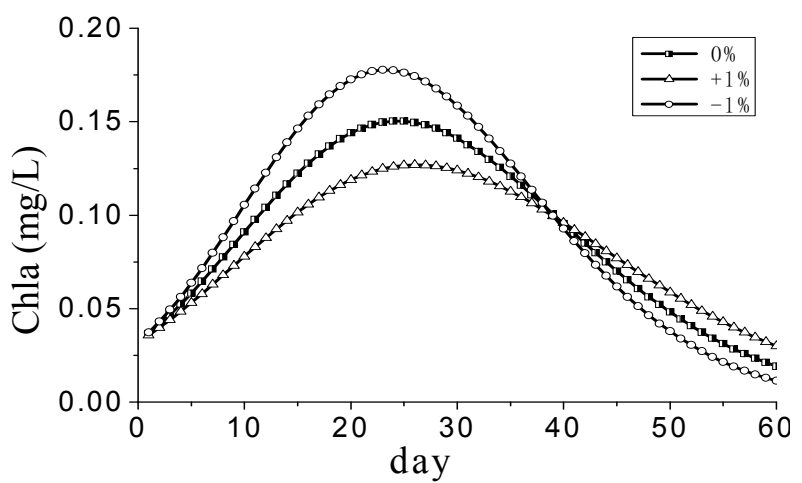

(f) coefficient of temperature influence on respiration

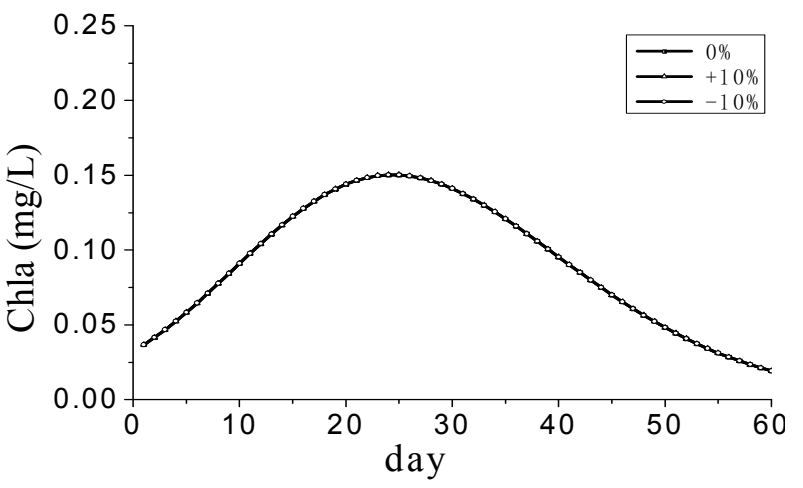

(h) half saturation constant for phosphorus

Fig. 2 Sumilated results of influence on the algae growth by eight factors

Simulated results show that the half-saturation constant of TN has little influence on algae growth, so does the settling velocity, while the other factors have great influence on it. Maximum growth rate of algae have great effect on algae growth. When adding the ratio by $10 \%$, chlorophyll 
concentration increases two to four times of the original value, which gives a relative sensitive coefficient of 30.5 . When reducing the ratio by $10 \%$, the relative sensitive coefficient is still in a high level of 8 . The increasing and decreasing of respiration rate of algae have opposite results to the change of algae growth rate, which verifies the opposite impacts of the growth and respiration. Death rate of algae has a little influence on chlorophyll concentration and the relative sensitive coefficient is about 2.5. Temperature of water is one of the main factors of influencing the algae growth because it affects both growth and breath of algae. When temperature is high, coefficient of temperature influence greatly affects the simulation results. When temperature is low, there is thin effect to the results. The half-saturation constant of $\mathrm{TN}$ has great effects on the algae growth and the relative sensitive coefficient is about 4.

Generally, the maximum growth rate of algae, respiration rate of algae, coefficient of temperature influence, and the half-saturation constant of TN are the main factors of influencing the algae growth. The maximum growth rate of algae has the biggest influence and infers that it is the key parameter in the algae growth model. Meanwhile, the results illustrate that water tempature and TN are the limiting factors of algae growth in Taihu lake.

\section{Conclusions}

Based on the cycle process of algae growth, an ecological dynamics model is established with emphasis of dominant algal growth by selecting chlorophyll, total phosphorus and TN as the critical water quality variables. The model consists of algae growth submodel, phosphorus cycle submodel and nitrogen cycle submodel. And the parameters used in the model are determined by considering the actual conditions in Taihu Lake.

The influences of main parameters on algae growth are analysed by simulation. The results show that maximum growth rate of algae, respiration rate of algae, coefficient of temperature influence, and half-saturation constant of $\mathrm{TN}$ are the major factors of influencing algae growth. $\mathrm{TP}$ and water temperature are the limiting factors of algae growth in Taihu Lake.

\section{Acknowledgements}

This work was financially supported by theNational Natural Science Funds of China for Distinguished Young Scholar (10825211).

\section{References}

[1] B.Q. Qin: Journal of Lake Sciences, Vol.10, No.4 (1998), p.1-9. (In Chinese)

[2] Q.J. Xu, B.Q. Qin and et al.: Journal of Lake Sciences, Vol.13, No.2 (2001), p.149-157. (In Chinese)

[3] Y.B. Liu, W.M. Chen and et al: Journal of Lake Sciences,Vol.10, No.4 (1998), , p.53-58. (In Chinese)

[4] L. Ding, J.Q. Wu and et al.: Ecological Engineering, Vol.31 (2007), p.200-206.

[5] K.W. Chau, H.S. Jin: Environmental Modeling and Assessment, Vol.4(1999), p.189-199.

[6] W.P. Hu, S.E. Jorgensen and F.B. Zhang: Ecological Modeling. Vol.190 (2006), p.367-398.

[7] J.Q. Mao, Q.W. Chen and Y.C. Chen: Journal of Environmental Science, Vol. 20 (2008), p. 278-284.

[8] Y. Pang, Q. Yao: General numerical study on atmosphere-water environment in Taihu Lake area, (Meteorological Press, Beijing 1998). (In Chinese)

[9] S.F. Zheng, S.W. Yang and X.C. Jin: Environmental Science, Vol.26, No.2 (2005), p. 153-156. (In Chinese) 
Advances in Environmental Science and Engineering

10.4028/www.scientific.net/AMR.518-523

An Ecological Dynamics Model of Algae Growth in Taihu Lake and the Analysis of its Influencing Factors

10.4028/www.scientific.net/AMR.518-523.4961 